\title{
Cycad Aulacaspis Scale, Aulacaspis yasumatsui Takagi (Insecta: Homoptera: Sternorrhyncha: Diaspididae) ${ }^{1}$
}

\author{
T. J. Weissling, F. W. Howard and A. B. Hamon²
}

\section{Introduction}

The cycad aulacaspis scale insect, Aulacaspis yasumatsui, was originally described from specimens collected on a Cycas sp., in Bangkok, Thailand, in 1972 (Takagi 1977). In Thailand, this armored scale is considered a pest of cycads, but is usually maintained in low densities by parasitoids (Tang et al. 1997). Aulacaspis yasumatsui was found in Miami, Florida in 1996, infesting cycads grown as ornamentals. King-sagos, Cycas revoluta Thumberg, the most popular cycad planted in this area, were highly infested with A. yasumatsui. Fairchild Tropical Garden and Montgomery Botanical Center, both of which have important world collections of cycads, were within the initially infested area. The rampant increase and spread of this scale insect in these collections threatened the survival of several rare and endangered species. An additional concern was the threat posed to a large concentration of nurseries in southern Florida that grow and ship cycads throughout the U. S. and abroad.

\section{Distribution}

The cycad aulacaspis scale insect is rapidly spreading through southern Florida. In 1996, this pest was on sago-palms in the Old Cutler Road section of southern Miami. By 1997, it had spread to Miami Beach and cities north of Miami, including Hialeah and North Miami Beach. In 1998, it had become widespread throughout Broward County, and has been reported as far north as some communities in Palm Beach County. Although scale insects may be spread short distances by wind dispersal of crawlers, we surmise that the long distance spread of this scale insect is by transport of infested plants. The cycad aulacaspis scale insect is spreading to new localities additional to Florida, having been reported recently in Hong Kong, Hawaii, and the Cayman Islands (Gillian Watson, The Natural History Museum, London, personal communication).

\section{Description}

The scales of mature A. yasumatsui females are white, 1.2 to1.6 $\mathrm{mm}$ long and highly variable in form. They tend to be pear-shaped but are often irregularly shaped, conforming to leaf veins, adjacent scales, and

1. This document is EENY-096, one of a series of Featured Creatures from the Entomology and Nematology Department, Florida Cooperative Extension Service, Institute of Food and Agricultural Sciences, University of Florida. Published: July 1999. This document is also available on Featured Creatures Website at http://creatures.ifas.ufl.edu. Please visit the EDIS Website at http://edis.ifas.ufl.edu. Additional information on these organisms, including many color photographs, is available at the Entomology and Nematology Department WWW site at http://entnemdept.ifas.ufl.edu/.

2. T. J. Weissling, F. W. Howard, University of Florida and A. B. Hamon, Florida Department of Agriculture, Division of Plant Industry.

The Institute of Food and Agricultural Sciences (IFAS) is an Equal Employment Opportunity - Affirmative Action Employer authorized to provide research, educational information and other services only to individuals and institutions that function without regard to race, creed, color, religion, age, disability, sex, sexual orientation, marital status, national origin, political opinions or affiliations. For information on obtaining other extension publications, contact your county Cooperative Extension Service office. Florida Cooperative Extension Service / Institute of Food and Agricultural Sciences / University of Florida / Larry R. Arrington, Interim Dean 
other objects. The scale of the male is 0.5 to $0.6 \mathrm{~mm}$ long, white, and elongate.

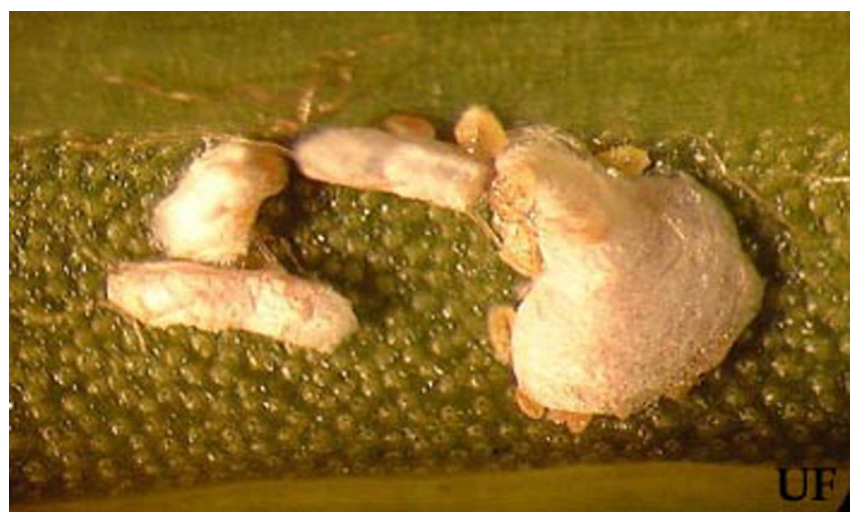

Figure 1. Male (left) and female (right) cycad aulacaspis scale, Aulacaspis yasumatsui Takagi. Credits: F. W. Howard, University of Florida

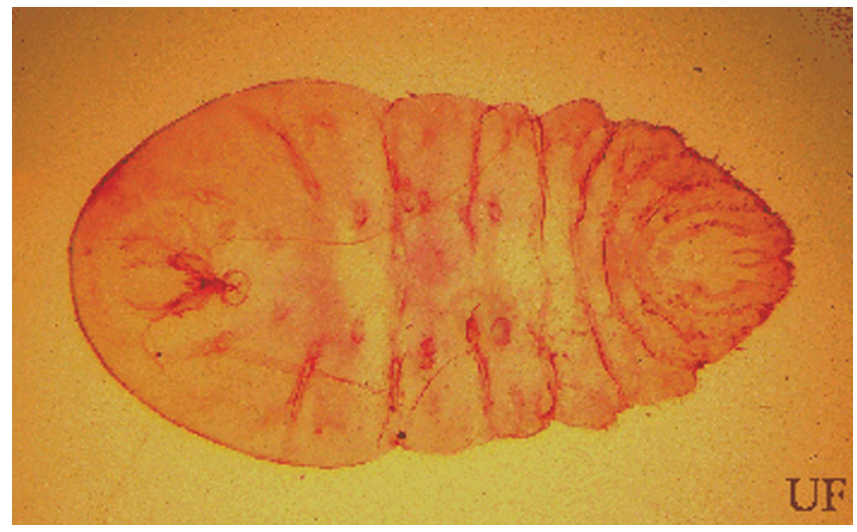

Figure 2. Slide-mounted mature female of the cycad aulacaspis scale, Aulacaspis yasumatsui Takagi. Credits: R. Scheffrahn, University of Florida

Upon casual observation in the field, the scale of A. yasumatsui females resembles that of the magnolia white scale, Pseudaulacaspis cockerelli (Comstock), which is also common on cycads in Florida.

However, the color of the insect body and of the eggs of A. yasumatsui is orange, except for recently molted individuals, which are yellow. The eggs and all stages of $P$. cockerelli are yellow. In addition, scales of $A$. yasumatsui are usually on the lower surface of leaves, while those of $P$. cockerelli are on the upper surface. The scale of Pinnaspis strachani (Cooley) (snow scale) females also resemble that of A. yasumatsui, but $P$. strachani is far less common on cycads than the other two scale insect species in south Florida.

\section{Biology}

The bionomics of the cycad aulacaspis scale insect was studied by Howard et al. (1999). Females go through three instars, and the average time from egg hatch to adult is 28 days. Females can lay more than 100 eggs which hatch in eight to 12 days at $25^{\circ} \mathrm{C}$. Most females do no live longer than 75 days.

The cycad aulacaspis scale is unusual in that it also infests the roots of its host plant at depths of up to $60 \mathrm{~cm}$ in the soil. Only a few other species of armored scale insects infest roots and they are generally located near the soil surface.

\section{Host Range}

Cycad aulacaspis scales have been observed infesting cycads in the Cutler Ridge area of Miami-Dade county (Table 1).

\section{Damage}

Damage initially appears as chlorotic spots, but most of the fronds eventually become brown and desiccated. Highly infested cycads are almost completely coated with a white crust that includes scales of live and dead insects. The scale insects are consistently more numerous on the lower than on the upper surfaces of leaflets, and in light infestations they occupy the lower leaf surfaces exclusively. Scales of males, which are less than half the length of scales of females, are nearly always more numerous than those of females. Crusts composed of several layers of scales of males are common on rachides, where up to 500 scales per $\mathrm{cm}^{2}$ have been observed.

Roots of containerized and planted cycads have been observed infested with $A$. yasumatsui males and females. In containerized cycads, the scale insects usually aggregate on primary roots (about $10 \mathrm{~mm}$ in dia) and singly or in groups of a few on secondary roots (about $2 \mathrm{~mm}$ in dia) near the container sides, i.e., near the soil-air interface. However, several scale insects have been observed on roots at $15 \mathrm{~cm}$ depth and several $\mathrm{cm}$ inward from the container sides. In the landscape, the scale insects have been observed at different depths on primary $(3 \mathrm{~cm}$ in diam) and secondary roots in groups of a few to several 
Table 1. Cycad aulacaspis scales have been observed infesting the following cycads in the Cutler Ridge area of Miami-Dade county.

\begin{tabular}{|c|c|c|c|}
\hline Family & Genus & Species & Geographic Origin \\
\hline \multirow[t]{8}{*}{ Cycadaceae } & Cycas & media R. Brown & Auatralia \& Papua New Guinea \\
\hline & & panzhihuaensis L. Shou and S. Y. Yang & China \\
\hline & & revoluta Thunberg & Japan to Ryukyu Islands \\
\hline & & rumphii Miguel & India, Southeast Asia, Oceania \\
\hline & & seemannii A. Braun & Oceania \\
\hline & & szehuanensis W.C. Cheng and L. K. Fu & China \\
\hline & & thouarsii R. brown ex Gaudich & Africa \\
\hline & & wadei Merrill & Phillippines \\
\hline \multirow[t]{13}{*}{ Zamiaceae } & Dioon & califanoi De Luca and Sabatori & Mexico \\
\hline & & edule Lindley & Mexico \\
\hline & & merolae De Luca & Mexico \\
\hline & & $\begin{array}{l}\text { rzedowskii De Luca, Moreti, Sabatori and } \\
\text { Vasquez }\end{array}$ & Mexico \\
\hline & & spinulosum Dyer (strobili only) & Mexico \\
\hline & & tomasellii De Luca var. sonorense & Mexico \\
\hline & Encephalartos & barteri Miguel (strobili only) & Africa \\
\hline & & ferox Bertoloni & Africa \\
\hline & & $\begin{array}{l}\text { hildebrandtii nr. Lembombensis A. Braun } \\
\text { and Bouch }\end{array}$ & Africa \\
\hline & & manikensis (Gilliland) & Africa \\
\hline & & pterogonus R. A. Dyer \& I. Verd & Africa \\
\hline & & whitelockii P.J. H. Hurter & Africa \\
\hline & Microcycas & $\begin{array}{l}\text { colocoma (Miguel) de Candolle (strobili } \\
\text { only) }\end{array}$ & Cuba \\
\hline Stangeriaceae & Stangeria & eriopus (Kunze) Baillon & Africa \\
\hline
\end{tabular}

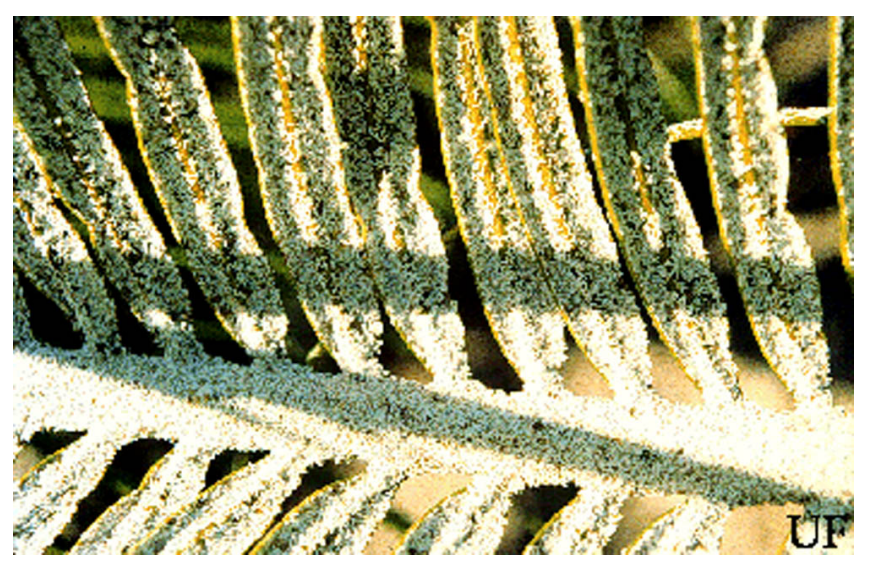

Figure 3. Frond of Cycas rumphii infested with the cycad aulacaspis scale, Aulacaspis yasumatsui Takagi. Credits: F. W. Howard, University of Florida

individuals from near the soil surface to a maximum depth of $60 \mathrm{~cm}$.
In addition to the injury caused, the scales of $A$. yasumatsui males and females are remarkably persistent. The dead scales detract from the appearance of ornamental plants. Cycads continue to appear to be highly infested after most of the scale insects have been killed because the scales do not readily drop off. Old scales are not easily removed by mechanical means, e.g., with brushes or high-pressure water sprays. Soaking excised fronds in soapy water overnight may loosen them, but similar solutions sprayed on cycad plants do not seem to have the same effect. A practical treatment that loosens old scales of armored scale insects would be a welcome development in horticulture and plant protection.

\section{Management}

The unusually dense populations and rapid spread of the cycad aulacaspis scale insect suggests 
that it was imported without natural enemies.

Occasionally ladybird beetle adults can be observed crawling on cycads infested with A. yasumatsui, but feeding has not been observed. Possibly, $A$.

yasumatsui sequesters defensive chemicals from its cycad hosts, which could be a deterrent to generalist predators.

Application of conventional insecticides such as cygon (dimethoate) have been effective in controlling this scale insect in some instances, but we have encountered situations in which these insecticides did not kill the pest. Imidacloprid has been effective at high rates in some trials, but not in all. We suspect cycads may undergo periods when their metabolic activity decreases so that they don't absorb systemic insecticides, but this is not proven.

So far, we have found that the most consistently effective treatment for controlling the cycad aulacaspis scale insect has been spraying them with oils. We have been using fish oil emulsion, but one of our colleagues has been using a petroleum-based horticultural oil with good results.

We mix the fish oil with water at a rate of 1 part oil to 100 parts of water. Since the cycad aulacaspis scale insect infests mostly the lower surfaces of the fronds, the spray must be directed there. A single cycad can be treated using a 1-quart hand sprayer or even a small squeeze bottle. We have found it useful to use a stick to lift each frond to spray the lower surface. The scale insects also commonly infest the stem, so we spray it as well as the fronds.

We haven't yet established how many times a cycad must be treated to control these scale insects. The fish oil treatment works best as a preventative that keeps scale insect crawlers (the larval stage) from settling on the plants. It is also somewhat effective in killing some of the mature females, which of course by laying eggs are the source of new the next generation of scale insects on the same or adjacent plants. When we have sprayed highly infested cycads once a week for several weeks, we have controlled the cycad aulacaspis scale insect. The sprays prevent establishment of new crawlers. Meanwhile, the mature females expend all of their eggs and die off.
As mentioned above, the scale itself is highly persistent, clinging to the leaf surface long after the insect beneath it is dead and dried up. For this reason, people often keep spraying plants long after they have killed all of the scales. Generally, old scales become infested with fungi and fall off gradually, and at the end of several months the plants are clean. Oils may help to loosen the scales, but we really don't know yet if they do. Frequent spraying with a garden hose may help wash off some of the old dead scales.

Cycad aulacaspis scale insect have a high potential to spread to new areas via plant movement, because one to a few fecund females hidden on the fibrous stem or on roots can easily escape detection. Once established, persistence will be required to keep populations managed.

\section{Selected References}

Hodges G, Howard FW, Buss EA. (February 2004). Update on Management Methods for Cycad aulacaspis scale. http://www.doacs.state.fl.us/pi/enpp/ento/ aulacaspis.html (11 March 2004).

Howard, F.W.. A. Hamon, M. McLaughlin, \& T. Weissling. 1999. Aulacaspis yasumatsui (Homoptera: Sternorrhyncha: Diaspididae), a scale insect pest of cycads recently introduced into Florida. Florida Entomol. 82: 14 - 27.

Meerow, A.W. and T. J. Weissling. Ornamental Pest Management at the Fort Lauderdale REC. http://www.ftld.ufl.edu/ornapest.htm (July 1999).

Mizell, R.F., D.E. Short and T.R. Fasulo. (May 1998). WoodyPest. UF/IFAS. http://woodypest.ifas.ufl.edu/ (July 1999).

Takagi, S. 1977. A new species of Aulacaspis associated with a cycad in Thailand (Homoptera: Cocoidea). Insecta Matsumurana New Series 11:63-72.

Tang, W., S-L Yang and P. Vatcharakorn. 1997. Cycads of Thailand: Nong Nooch Tropical Garden and the Cycad Conservation Company, Bangkok. 34 pp. 